\title{
IMPLEMENTAÇÃO DE PLANOS DE AÇÕES ARTICULADAS MUNICIPAIS: ACHADOS DE UMA PESQUISA DE AVALIAÇÃO
}

\author{
Nalú Farenzena* \\ Alexandre José Rossi ${ }^{* *}$ \\ Maria Goreti Farias Machado ${ }^{* *}$ \\ Neusa Chaves Batista ${ }^{* * * *}$
}

\begin{abstract}
RESUMO
$\mathrm{O}$ artigo apresenta resultados de uma pesquisa de avaliação da implementação de planos de ações articuladas (PAR) numa amostra de 95 municípios dos estados de Alagoas, Paraíba, Rio Grande do Sul e Santa Catarina, no período de 2008 a 2010. Foi realizada uma avaliação de resultados em sentido estrito, que envolveu elementos contextuais, situações de execução das ações do PAR e condicionantes que limitavam a execução. $\mathrm{O}$ texto descreve os marcos e os procedimentos da avaliação e expõe um panorama da execução do PAR no conjunto dos municípios e na amostra de cada estado. No período analisado, embora tenha havido uma evolução positiva, parte considerável das ações não foi concluída, o que é explicado por dificuldades na oferta de programas e ações por parte do Ministério da Educação e por dificuldades de diversas ordens no âmbito dos governos locais. Com base na pesquisa realizada são destacados, nos comentários finais, características e desafios da implementação de políticas intergovernamentais, bem como alguns elementos para pensar a pesquisa em políticas públicas.
\end{abstract}

Palavras-chave: Plano de Ações Articuladas. Política Educacional. Avaliação de Políticas Educacionais.

\footnotetext{
* Doutora em Educação pela Universidade Federal do Rio Grande do Sul (UFRGS), 2001. Professor associado nível 2 do Departamento de Estudos Especializados da Faculdade de Educação da Universidade Federal do Rio Grande do Sul (UFRGS). Endereço para correspondência: Av. Paulo Gama, s/n, Faculdade de Educação, sala 1004, Farroupilha - Porto Alegre-RS. CEP: 90046-900. nalu.farenzena@gmail.com

** Mestre em Educação pela Universidade Federal do Rio Grande do Sul, 2010. Doutorando do Programa de Pós-Graduação em Educação da Universidade Federal do Rio Grande do Sul (UGRGS). Professor na área de políticas e gestão da educação em cursos de pós-graduação da Unisinos, da Faccat e da Escola de Gestores da Educação Básica da UFRGS. Endereço para correspondência: Av. Paulo Gama, s/n, Faculdade de Educação, sala 1004, Farroupilha - Porto Alegre-RS. CEP: 90046-900. aj_rossi@yahoo.com.br

*** Doutora em Educação pela Universidade Federal do Rio Grande do Sul, 2012. Técnica em assuntos educacionais (UFRGS). Endereço para correspondência: Av. Paulo Gama, s/n, Faculdade de Educação, sala 1004, Farroupilha - Porto Alegre-RS. CEP 90046-900.mgoretimachado@gmail.com

${ }^{* * * *}$ Doutora em Educação pela Universidade Federal do Rio Grande do Sul, 2009. Professor adjunto nível 2 do Departamento de Estudos Básicos da Faculdade de Educação da Universidade Federal do Rio Grande do Sul (UFRGS). Endereço para correspondência: Av. Paulo Gama, s/n, Faculdade de Educação, sala 1002, Farroupilha - Porto Alegre-RS. CEP: 90046-900. neuchaves@gmail.com
} 


\section{ABSTRACT \\ IMPLEMENTATION OF MUNICIPAL JOINT ACTION PLANS: FINDINGS OF AN EVALUATION RESEARCH}

The article presents results of an evaluation research of the joint action plans (JAP) implemented in a sample of 95 cities in the Brazilian states of Alagoas, Paraíba, Rio Grande do Sul and Santa Catarina, from 2008 to 2010. An evaluation of results in strict sense was realized, involving contextual elements, execution situations of JAP actions and factors that limited the fulfilment. We describe milestones and evaluation procedures and present an overview of JAP implementation in grouped and individual samples from each state. Over the period analyzed however, there was a positive development, a considerable part of the planned actions has not been completed, which is explained by difficulties in the offer of programs and actions by the Ministry of Education and also by various complications in the context of local governments. Based on the research, the final reflections highlight characteristics and challenges of implementing intergovernmental policies, as well as some elements to think about public policies research.

Keywords: Joint Action Plan. Educational Policy. Evaluation of Educational Policies.

\section{Introdução}

O Plano de Metas Compromisso Todos pela Educação (Plano de Metas) é uma política pública que integra o Plano de Desenvolvimento da Educação (PDE), lançado em 2007 pelo Ministério da Educação (MEC). O Plano de Metas, cujas linhas gerais estão incluídas no Decreto $\mathrm{n}^{\circ}$ 6.094/07, tem como objetivo a melhoria da qualidade da educação básica, pautando-se em 28 diretrizes, as quais abrangem aspectos relacionados ao acesso e à permanência na escola, à organização do trabalho pedagógico, à formação e à carreira dos profissionais da educação, à gestão das escolas e das redes de ensino, entre outros. O Plano de Metas é uma política intergovernamental. Proposta pelo governo federal, conta com sua intervenção na promoção e na implementação das ações, mas envolve, igualmente, com as mesmas funções, as redes estaduais e municipais de ensino (BRASIL, 2007).

No âmbito do Plano de Metas, estados e municípios elaboraram planos de ações articuladas (PAR) 2008-2011, na perspectiva de cumprimento das referidas diretrizes e, por consequência, de evolução positiva do Índice de Desenvolvimento da Educação básica (Ideb). Todos os municípios que aderiram ao Plano de Metas podiam elaborar o PAR 2008-2011, mas aqueles com Ideb abaixo da média nacional, chamados de municípios priorizados, receberam assistência técnica, por meio de profissionais que atuaram em acordos firmados entre o MEC e universidades ou outras instituições, para elaboração do PAR e para realizar o monitoramento da execução de suas ações.

Numa parceria entre a Universidade Federal do Rio Grande do Sul (UFRGS) e o MEC, foi desenvolvido, de 2007 a 2010, um projeto de extensão para a oferta da assistência técnica a municípios referida acima; o projeto denominou-se Apoio ao Desenvolvimento da Educação Básica. Nos anos de 2009 e 2010, o projeto abrangeu redes municipais de ensino priorizadas dos estados do Rio Grande do Sul (RS), Santa Catarina (SC), Alagoas $(\mathrm{AL})$ e Paraíba (PB). Parte da equipe desse projeto de extensão realizou uma pesquisa de avaliação da implementação de planos de ações articuladas 2008-2011 de uma amostra de 95 municípios priorizados dos quatro estados abrangidos no projeto de extensão de 2009 e $2010^{1}$.

Neste artigo, apresentamos achados, por nós considerados como de maior relevo, na avaliação que empreendemos acerca da implementação do PAR, abrangendo: uma reflexão sobre o escopo da avaliação realizada, sublinhando sua delimitação e

$\overline{1 \text { Os resultados da }}$ pesquisa foram publicados em Farenzena (2012). 
alguns de seus limites; um panorama da implementação do PAR, agregando dados de todos os municípios da amostra; uma síntese dos resultados da avaliação realizada em cada estado. Nos comentários finais, fazemos algumas reflexões sobre a pesquisa de análise e de avaliação de políticas públicas.

\section{A amostra e as dimensões da avaliação}

No Sistema de Monitoramento de Informações do Ministério da Educação (Simec), há um módulo específico para o PAR. Entre outros campos, esse módulo, no que concerne ao PAR 2008-2011, contém indicadores qualitativos, com foco em quatro dimensões - gestão educacional, formação de professores e dos profissionais de serviço e apoio escolar, práticas pedagógicas e avaliação, infraestrutura física e recursos pedagógicos. Nessas dimensões estão distribuídos 52 indicadores de diagnóstico e as ações e subações de planejamento a eles relacionadas - uma ação gerada, quando um item do diagnóstico apontou situação insuficiente ou crítica, desdobrava-se em diversas subações, podendo variar de três ou quatro a mais de 30 subações dentro de uma ação. No módulo PAR 2008-2011 também se encontra o monitoramento, para registro da execução do $\mathrm{PAR}^{2}$.

Para realizar a avaliação da implementação do PAR, trabalhamos com uma amostra de municípios dos quatro estados, abrangendo 95 localidades $^{3}$. Conforme consta na Tabela 1, esses 95 municípios representam 19\% dos 491 municípios priorizados dos quatro estados: contamos com 10 de Alagoas (10\% dos municípios priorizados desse estado), 35 da Paraíba (18\% dos municípios priorizados), 38 do Rio Grande do Sul (28\% dos municípios priorizados) e 12 de Santa Catarina (19\% dos municípios priorizados).

Nossa pesquisa focou a descrição e a interpretação da implementação das ações ${ }^{4}$ do PAR, de 2008 até o primeiro semestre de 2010. Categorizamos as situações de realização das ações registradas no PAR de cada município, bem como fatores que dificultavam sua execução.

Tabela 1 - Número de municípios priorizados e amostra final da pesquisa, por estado

\begin{tabular}{l|l|l|l}
\hline \multirow{2}{*}{ Estado } & \multirow{2}{*}{$\begin{array}{l}\mathrm{N}^{\mathrm{o}} \text { de municípios } \\
\text { priorizados }\end{array}$} & \multicolumn{2}{|l}{ Amostra final } \\
\cline { 3 - 4 } & 100 & $\mathrm{~N}^{\mathrm{o}}$ & $\%$ \\
\hline $\mathrm{AL}$ & 190 & 10 & $10 \%$ \\
\hline $\mathrm{PB}$ & 138 & 35 & $18 \%$ \\
\hline $\mathrm{RS}$ & 63 & 38 & $28 \%$ \\
\hline $\mathrm{SC}$ & 491 & 12 & $19 \%$ \\
\hline Total & 49 & $19 \%$ \\
\hline
\end{tabular}

Fonte: Simec (2012).

Optamos por empreender uma avaliação de resultados em sentido estrito, quer dizer, analisar em que medida as ações estavam sendo executadas, combinada com uma interpretação dos condicionantes que limitavam essa execução. Entendemos que seria prematuro avaliar efeitos e impactos, pois a implementação do PAR era recente.

Em suma, trabalhamos com o objetivo de avaliar o processo de implementação do PAR levando em conta as seguintes dimensões: (1) elementos contextuais; (2) processo de implementação do PAR,
2 Os planos foram elaborados por equipes locais; os municípios priorizados contaram com o apoio técnico já referido. Grande parte dos municípios brasileiros elaborou seus planos em 2008 e 2009. Em 2009 e 2010, as redes públicas realizaram monitoramento da execução do PAR; da mesma forma, os municípios priorizados contaram com assistência técnica direta de acompanhamento de seus monitoramentos.

3 Detalhes em relação aos procedimentos e à seleção dos municípios podem ser encontrados em Farenzena (2012).

4 Cabe esclarecer que cada ação do PAR desdobra-se em subações. Nossos levantamentos e interpretações focaram cada uma das subações previstas no PAR de cada município; portanto, embora falemos aqui de ações, de fato a referência é às subações, pois somente em relação a essas foi possível identificar situações ou estados de execução e limites à execução. 
que abrange a situação de execução das ações, por semestre, e condicionantes que limitam a realização das ações.
No Quadro 1 estão registrados os elementos contextuais que serviram de base para interpretações realizadas ao longo do processo avaliativo.

Quadro 1 - Elementos contextuais levados em conta na pesquisa

\begin{tabular}{|c|c|}
\hline Elementos do contexto estadual & $\begin{array}{l}\text { Elementos do contexto dos municípios da } \\
\text { amostra }\end{array}$ \\
\hline $\begin{array}{l}\mathrm{N}^{\circ} \text { de municípios do estado e sua distribuição } \\
\text { regional e } \mathrm{n}^{\circ} \text { de municípios priorizados e sua } \\
\text { distribuição regional }\end{array}$ & $\begin{array}{l}\text { Localização geográfica, com identificação da } \\
\text { mesorregião }\end{array}$ \\
\hline $\begin{array}{l}\text { Características gerais da elaboração do PAR e } \\
\text { monitoramento do PAR no estado (quais foram } \\
\text { os apoios disponibilizados) }\end{array}$ & $\begin{array}{l}\text { Características socioeconômicas e } \\
\text { demográficas: população, índice de } \\
\text { desenvolvimento humano municipal (IDH-M) } \\
\text { e Produto Interno Bruto (PIB) per capita }\end{array}$ \\
\hline \multirow{2}{*}{$\begin{array}{l}\text { Informações sobre as ofertas de formação } \\
\text { ligadas ao PAR no estado }\end{array}$} & $\begin{array}{l}\text { Características da oferta educacional: } \mathrm{n}^{\circ} \text { de } \\
\text { escolas; } \mathrm{n}^{\circ} \text { de alunos; percentual de } \\
\text { atendimento do Ensino Fundamental } \\
\text { municipal; Ideb }\end{array}$ \\
\hline & $\begin{array}{l}\text { Características político-institucionais: } \\
\text { existência ou não de sistema municipal de } \\
\text { ensino, conselho municipal de educação e } \\
\text { plano municipal de educação }\end{array}$ \\
\hline
\end{tabular}

Fonte: Elaborado pelos autores deste artigo.

Já a segunda dimensão destacou o processo de implementação do PAR: a) pela situação de execução das subações, por semestre (primeiro de 2008 ao primeiro de 2010), com base nas situações previstas no próprio Simec para o monitoramento do PAR: não iniciada, em andamento, concluída, suspensa, cancelada; b) por condicionantes que limitam a execução das subações. Os condicionantes foram previamente definidos tomando-se por base um estudo exploratório em alguns planos de ações articuladas, bem como apoiado no conhecimento da equipe a respeito da realização do PAR em redes municipais. Foram considerados condicionantes que limitam a execução da ação/subação os que são pontuados a seguir.

a) Políticos: mudanças nos cargos de confiança; dificuldades na aprovação de leis; veto ou falta de apoio do prefeito ou outros administradores a propostas do PAR; resistência por parte dos profissionais ou comunidades à implementação da subação.

b) Financeiros: impossibilidade de prever recursos na lei orçamentária; falta de recursos.

c) Ações simultâneas desenvolvidas pelo município: ações que incidem nos problemas/situações avaliadas como limitações no PAR e que substituem as ações previstas no PAR; a limitação está sendo enfrentada, mas com outra ação que não a prevista no PAR.

d) Falta de informação: falta de informação sobre um programa, uma lei; aguardo de informações esperadas do MEC (ficar "esperando contato do MEC").

e) Inexistência ou atendimento parcial do programa/ação pelo MEC.

f) Dificuldades de ordem técnico-administrativa e operacional: falta de pessoa especializada em algo; falta de articulação com setores da prefeitura; falta de pessoal 
para implementar a subação; dificuldades de articulação com outros municípios; impossibilidade de realizar a subação por falta de instalações ou equipamentos.

g) Não prioridade à subação: falta de tempo, deixar de lado, imobilismo, informações vagas que denotem essa não atribuição de prioridade; profissionais não querem participar (por exemplo, de programa de formação).

\section{h) Outros.}

A Figura 1 sintetiza dimensões, temporalidade e categorias da avaliação.

Figura 1 - Principais informações disponibilizadas nos relatórios de implementação do PAR gerados pelo sistema de registro e consolidação dos dados da pesquisa

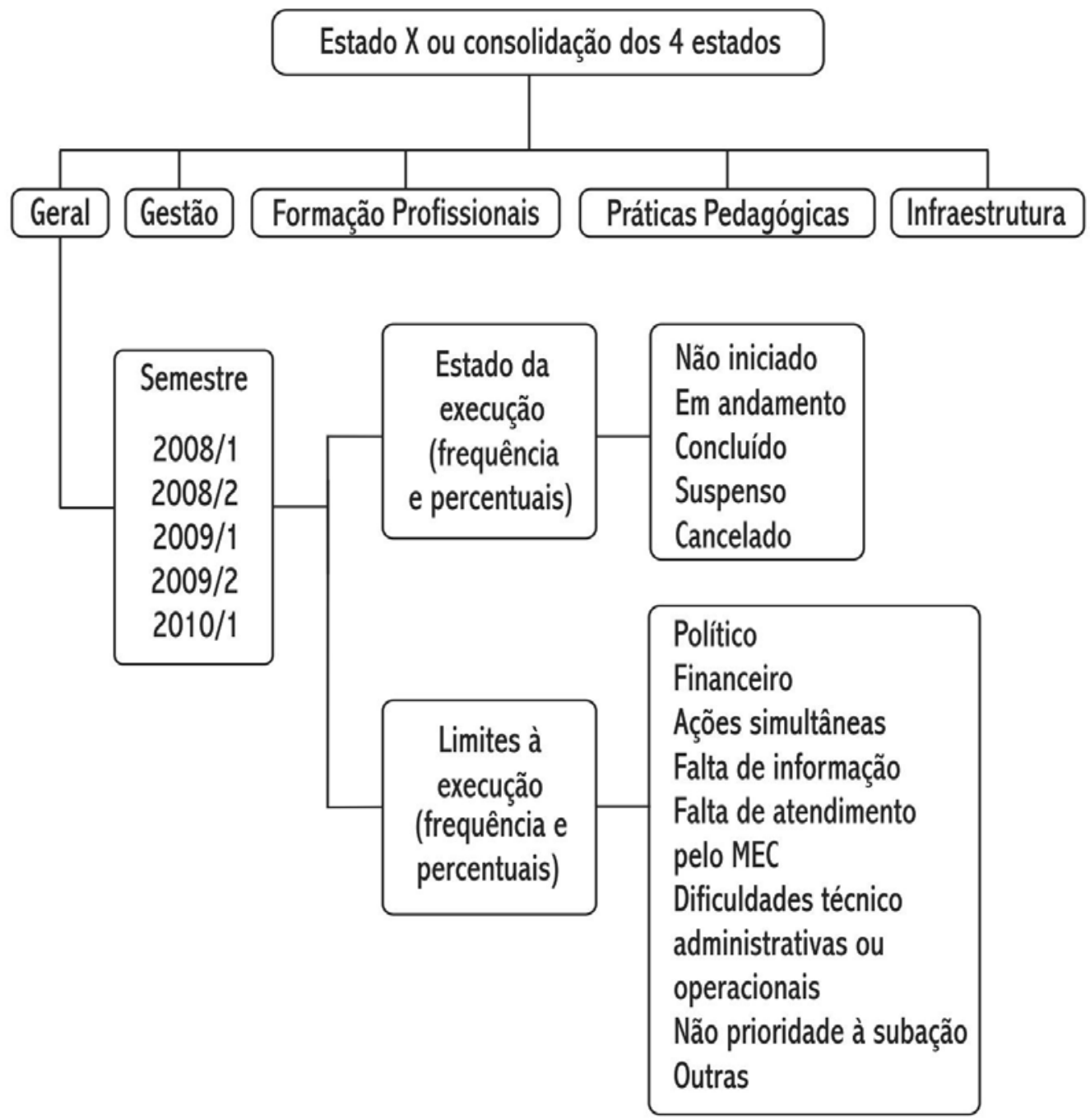

Fonte: Farenzena (2012, p. 25). 


\section{O que foi avaliado? E o que não foi avaliado?}

No início da investigação, elaboramos um marco conceptual do PAR; definimos um processo que combina ações, resultados e objetivos, conforme resumido no Quadro $2^{5}$. Temos clareza de que essa representação simplifica processos envolvidos na implementação do PAR. Mesmo assim, sua construção permitiu que chegássemos a algumas definições sobre o que era viável avaliarmos, de acordo com as características da própria política e com nossas possibilidades de investigação.

Segundo Mokate (2000, p. 13), "O marco con- ceptual se converte no mapa do processo de monitoramento e avaliação. Indica-nos os fenômenos que temos que analisar e acompanhar e guia nossa definição de necessidades de informações" (tradução nossa). A construção da cadeia de objetivos do Plano de Metas/PAR, que supõe relacionamento causal entre cada elo, foi decisiva para desenharmos a pesquisa de avaliação viável, ou seja, de acordo com a temporalidade da elaboração e implementação do PAR, as informações disponíveis e as condições de acesso a essa informação. Abarcamos os dois primeiros elos da cadeia - atividades e produtos/resultados em sentido estrito (as células sombreadas no Quadro 2).

Quadro 2 - Marco conceptual do Plano de Metas/PAR

\begin{tabular}{|c|c|c|c|}
\hline Atividades & $\begin{array}{l}\text { Produtos/resultados em } \\
\text { sentido estrito (objetivos } \\
\text { operativos) }\end{array}$ & $\begin{array}{l}\text { Efeitos (objetivos } \\
\text { intermediários) }\end{array}$ & $\begin{array}{l}\text { Impactos (objetivos } \\
\text { finais) }\end{array}$ \\
\hline \multirow[t]{2}{*}{$\begin{array}{l}\text { Elaboração do } \\
\text { PAR; realização } \\
\text { das atividades } \\
\text { para chegar ao } \\
\text { resultado } \\
\text { definido para } \\
\text { cada ação } \\
\text { (atividades a } \\
\text { serem executadas } \\
\text { pelo MEC e } \\
\text { pelos } \\
\text { municípios). }\end{array}$} & $\begin{array}{l}\text { Resultados referentes a: } \\
\text { elaboração de documentos } \\
\text { (edital, diagnóstico, plano, } \\
\text { calendário etc.); realização de } \\
\text { reuniões, capacitações, } \\
\text { qualificações de pessoal; } \\
\text { elaboração e/ou execução de } \\
\text { planos, tecnologias, projetos, } \\
\text { atendimentos; recebimento ou } \\
\text { aquisição de bens de consumo } \\
\text { ou de capital; construção, } \\
\text { reforma ou adaptação de } \\
\text { prédios e instalações. }\end{array}$ & \multirow[t]{2}{*}{$\begin{array}{l}\text { Utilização efetiva } \\
\text { de todos os } \\
\text { recursos gerados } \\
\text { (de gestão, de } \\
\text { qualificação de } \\
\text { profissionais, de } \\
\text { propostas e } \\
\text { práticas } \\
\text { pedagógicas, e de } \\
\text { infraestrutura), } \\
\text { seja nos } \\
\text { sistemas/redes de } \\
\text { ensino, seja nas } \\
\text { escolas ou salas de } \\
\text { aula. }\end{array}$} & \multirow[t]{2}{*}{$\begin{array}{l}\text { Melhoria da } \\
\text { qualidade da } \\
\text { educação (sua } \\
\text { expressão no Ideb, } \\
\text { ou seja, melhoria } \\
\text { das taxas de } \\
\text { aprovação e do } \\
\text { desempenho dos } \\
\text { alunos no Saeb e na } \\
\text { Prova Brasil). }\end{array}$} \\
\hline & $\begin{array}{l}\text { Condicionantes da situação de } \\
\text { execução das ações. }\end{array}$ & & \\
\hline
\end{tabular}

Fonte: Farenzena (2012, p. 154).

Cabe observar que esse marco conceptual é uma primeira versão, especialmente no que diz respeito

5 Para a elaboração do marco conceptual do Plano de Metas/ PAR, baseamo-nos em Mokate (2000) e Cohen e Franco (2008). à identificação do objetivo finalístico. Este expressa a transformação desejada: melhoria da qualidade da educação. É um objetivo amplo e difuso, sujeito a diferentes significações, pois o que é qualidade da educação? Quais seriam os indicadores que atestariam manutenção, melhora ou piora na qualidade da 
educação? No bojo de tantas ações públicas desenvolvidas paralelamente às ações propostas no PAR, como isolar a contribuição da efetivação das ações do PAR à melhoria da qualidade da educação? Se nos próximos anos o Ideb evoluir positivamente, $\mathrm{o}$ que a execução do PAR tem a ver com isso?

Melhorar a qualidade da educação é um objetivo que agrega apoios, afinal, quem é contra a melhoria da qualidade da educação? Contudo permanece como um desafio para nós, pesquisadores - no caso da avaliação da implementação do Plano de Metas/PAR -, a delimitação de objetivos finais mais modestos para empreendermos a avaliação de seus impactos.

Ao apreciarmos em que medida as ações e as subações estavam sendo executadas, e que dificuldades se apresentaram, supomos que a execução produziria efeitos na melhoria da qualidade da edu- cação. A extensão do PAR, a quantidade de ações planejadas, bem como a necessidade de interpretações articuladas foram condicionantes marcantes para as decisões tomadas quanto à natureza, às finalidades, aos critérios e aos focos da pesquisa.

\section{Como se apresentou a execução das ações do PAR nos municípios da amostra?}

Reunimos aqui dados dos 95 municípios que integraram a amostra. Uma vez que é expressiva a quantidade de informações disponibilizada quando da geração de relatórios do banco de dados da pesquisa, optamos por apresentar apenas informações referentes ao conjunto das ações, sem especificações por dimensão. Comecemos pelo estado de execução das ações, de acordo com as categorias utilizadas.

Quadro 3 - Distribuição percentual das ações por situação de execução, por semestre - municípios da amostra

\begin{tabular}{|l|l|l|l|l|l|}
\hline Semestre/situação de execução & $2008 / 1$ & $2008 / 2$ & $2009 / 1$ & $2009 / 2$ & $2010 / 1$ \\
\hline Não iniciada & $70 \%$ & $65 \%$ & $65 \%$ & $60 \%$ & $57 \%$ \\
\hline Em andamento & $20 \%$ & $23 \%$ & $27 \%$ & $31 \%$ & $35 \%$ \\
\hline Concluída & $8 \%$ & $9 \%$ & $5 \%$ & $7 \%$ & $6 \%$ \\
\hline Suspensa ou cancelada & $2 \%$ & $3 \%$ & $3 \%$ & $2 \%$ & $2 \%$ \\
\hline
\end{tabular}

Fonte: Simec (2012).

Como pode ser observado no Quadro 3, do primeiro semestre de $2008(2008 / 1)$ ao primeiro semestre de 2010 (2010/1) houve um movimento progressivo na execução das ações - as ações em andamento passaram de uma proporção de $20 \%$ em 2008/1 para 35\% em 2010/1. Mesmo assim, as ações não iniciadas sempre predominaram, variando as proporções - representavam 70\% em 2008/1, 65\% em 2009/1 e 57\% em 2010/1. O moroso processo de execução das ações fica ainda mais evidente quando olhamos a proporção de ações concluídas, com uma variação, nos semestres, de 5\% (em 2009/1) a 9\% (em 2008/2). Portanto, embora seja observada uma evolução positiva na execução das ações, esta ocorreu num ritmo bastante aquém do planejado - muitas ações não foram executadas de acordo com o cronograma registrado no PAR, acumulando-se, no período, ações não concluídas. $O$ primeiro semestre de 2010 é emblemático dessa condição, pois 57\% das ações estavam com o status não iniciada, num semestre em que, além das ações programadas para iniciarem ou serem ali concluídas, acumularam-se ações programadas, porém não iniciadas, dos semestres anteriores.

Que fatores têm influenciado essa progressão lenta? No âmbito da nossa pesquisa, conseguimos elaborar uma categorização de limites à execução das ações programadas no PAR; a distribuição percentual desses limites para os 95 municípios da amostra encontra-se no Quadro 4. 
Quadro 4 - Distribuição percentual dos limites à execução das ações, por semestre - municípios da amostra

\begin{tabular}{|l|l|l|l|l|l|}
\hline $\begin{array}{l}\text { Semestre/limites à execução } \\
\text { do PAR }\end{array}$ & $2008 / 1$ & $2008 / 2$ & $2009 / 1$ & $2009 / 2$ & $2010 / 1$ \\
\hline Político & $8 \%$ & $10 \%$ & $3 \%$ & $2 \%$ & $2 \%$ \\
\hline Financeiro & $3 \%$ & $3 \%$ & $4 \%$ & $5 \%$ & $5 \%$ \\
\hline $\begin{array}{l}\text { Ações simultâneas do } \\
\text { município }\end{array}$ & $2 \%$ & $2 \%$ & $2 \%$ & $3 \%$ & $2 \%$ \\
\hline Falta de informação & $10 \%$ & $8 \%$ & $9 \%$ & $8 \%$ & $6 \%$ \\
\hline $\begin{array}{l}\text { Falta de atendimento pelo } \\
\text { MEC }\end{array}$ & $29 \%$ & $35 \%$ & $47 \%$ & $50 \%$ & $55 \%$ \\
\hline $\begin{array}{l}\text { Dificuldades de ordem } \\
\text { técnica ou operacional }\end{array}$ & $21 \%$ & $21 \%$ & $18 \%$ & $16 \%$ & $13 \%$ \\
\hline Não prioridade à subação & $16 \%$ & $12 \%$ & $8 \%$ & $8 \%$ & $8 \%$ \\
\hline Outras & $11 \%$ & $8 \%$ & $8 \%$ & $8 \%$ & $9 \%$ \\
\hline
\end{tabular}

Fonte: Simec (2012).

A falta de atendimento ou atendimento parcial pelo MEC de programas ou ações de sua responsabilidade, seja de assistência técnica, seja de assistência financeira, sobressai como o principal obstáculo nos cinco semestres analisados. Esse é um limite cuja participação percentual aumentou de semestre a semestre, na medida em que uma quantidade maior de ações foi programada.

As dificuldades de ordem técnico-administrativa ou operacional compreendem uma série de lacunas ou fragilidades: falta de pessoa especializada para executar uma ação; falta de articulação com setores da prefeitura; falta de pessoal para implementar a subação; dificuldades de articulação com outros municípios; impossibilidade de realizar a ação por falta de instalações ou equipamentos. É a categoria de limites que ficou em segundo lugar, embora sua participação relativa tenha diminuído à medida que aumentou o não atendimento de demandas registradas no PAR por parte do MEC.

A categoria de limite não prioridade à subação - com participação percentual que variou de $16 \%$ a $8 \%$ - foi atribuída quando detectadas situações ou justificativas de postergação na execução, por exemplo, por falta de tempo para agir, pela incidência de informações vagas que denotassem a não priorização, ou quando os profissionais não queriam participar de uma ação (por exemplo, de programa de formação).
Registros de limite ligado à falta de informação - abrangendo falta de informação sobre um programa/ação, ou uma norma, ou, ainda, aguardo de informações esperadas do MEC - foram encontrados ao longo dos semestres, diminuindo, contudo, sua participação percentual no período. Nos registros do monitoramento do PAR feito pelas equipes das secretarias municipais de educação, muitas vezes encontramos ações não iniciadas, justificadas por "estamos aguardando contato do MEC", quando era evidente que esse contato não seria necessário para agir.

Limites agrupados na categoria político apresentaram-se também em todos os semestres; entraram nessa categoria as situações de mudanças nos cargos de confiança, dificuldades na aprovação de leis, veto ou falta de apoio do prefeito ou outros administradores a propostas do PAR, resistência por parte dos profissionais ou comunidades à implementação da ação. As mudanças na composição das equipes das secretarias de educação foram o principal componente dessa categoria a constituir obstáculo no que tange à execução progressiva e continuada das ações do PAR.

A falta de recursos ou a impossibilidade de prever recursos na lei orçamentária para execução de ações constituíram os descritores do limite chamado de financeiro, cuja participação percentual progrediu nos semestres - representava 3\% em 2008/1 e passou a $5 \%$ em 2010/1. 
Outra categoria que definimos como limite foi a de ações simultâneas desenvolvidas pelo município (com representação percentual de $2 \%$ ou $3 \%$ nos semestres considerados), que abrangeu o desenvolvimento de ações que incidiam na superação dos problemas/situações avaliados como críticos no PAR e que substituíam as ações previstas no PAR; quer dizer, o problema estava sendo enfrentado, mas com outra ação que não a prevista no PAR.

A categoria outros agrupou, na maioria das vezes, aquelas situações em que não foi possível detectar os motivos para a postergação de execução das ações, o que é compreensível no quadro da existência de muitas ações a serem executadas, como também pelo fato de que não levantamos informações diretamente com as equipes locais. Desse panorama, podemos destacar alguns achados relevantes.

Por um lado, a expressiva incidência do limite falta de atendimento ou atendimento parcial pelo MEC de programas ou ações evidencia as dificuldades do próprio ente propositor da política em dar conta de responsabilidades com as quais se comprometeu, dentro de um cronograma acordado, seja por tê-las previsto no PAR, seja por tê-las inserido nos termos de cooperação gerados quando da finalização do PAR.

Por outro lado, os limites dificuldades de ordem técnico-administrativa ou operacional, não prioridade à subação, político e financeiro concernem a fragilidades encontradas no âmbito local. É difícil, inclusive, encaixar os obstáculos à execução de ações do PAR numa ou noutra categoria, pois as justificativas apresentam-se mais na interseção de duas ou mais categorias. Por exemplo, a falta de pessoal para executar ações, que foi enquadrada na categoria dificuldades de ordem técnico-administrativa ou operacional, bem pode ter relação com o limite financeiro a falta de recursos financeiros para alocar mais funcionários nas secretarias de educação, ou para proporcionar formações às equipes administrativas. De todo modo, a incidência desses limites manifesta o enorme desafio que é a qualificação político-administrativa local-municipal diante de precariedades financeiras e institucionais e de contextos heterogêneos e desiguais. Essa qualificação envolve tanto o fortalecimento financeiro das administrações locais quanto o fortalecimento da gestão local da educação, no que diz respeito a constituir estruturas mais sólidas nas secretarias de educação para a proposição e a execução de políticas educacionais continuadas e referenciadas no contexto local, com o PAR e para além do PAR.

$O$ limite falta de informação contempla tanto dificuldades do próprio MEC em fazer chegar aos municípios informações que lhes permitiriam acessar uma ação de assistência - por exemplo, realização de formações, busca de materiais disponibilizados na internet, prazo para adesão a programas - quanto dificuldades de parte das equipes locais das secretarias de educação em compreender o modo de execução das ações - principalmente em compreender que certas ações deveriam ser executadas sem a interveniência do MEC. Situações que se encaixaram nessa categoria, entretanto, foram diminuindo ao longo do período, o que atribuímos ao aperfeiçoamento dos canais de comunicação do MEC com as secretarias de educação e à intervenção dos técnicos que atuaram em apoio às equipes locais no monitoramento do PAR.

\section{Quais foram os principais achados nos estudos dos estados?}

É difícil fazer escolhas dos principais achados nos estudos específicos de cada estado. Mesmo assim, correndo o risco de deixar de lado aspectos relevantes, sublinhamos nesta seção aspectos relacionados à implementação do PAR que foram selecionados de acordo com as peculiaridades de cada estado ${ }^{6}$. Como aspectos gerais, destacamos: o ineditismo do PAR, pois é uma possibilidade de os municípios elaborarem um plano para a educação que prevê ações continuadas e conjuntas com o MEC; o PAR fundamenta-se numa concepção de aprimoramento do regime de colaboração intergovernamental, constitui-se como grande aliado nas ações de âmbito local, por aportar, por meio de assistência técnica e financeira do MEC aos municípios, um volume adicional e mais criterioso de recursos. E vejamos agora cada um dos estados.

6 O estudo detalhado da implementação do PAR em Alagoas, Paraíba, Rio Grande do Sul e Santa Catarina encontra-se, respectivamente, em Machado et al (2012), França et al (2012), Batista et al (2012) e Rossi et al (2012) 
Alagoas. Todos os 102 municípios alagoanos são considerados prioritários pelo MEC por apresentarem Ideb abaixo da média nacional. Por consequência, receberam assistência técnica para a elaboração do PAR e no acompanhamento do monitoramento do plano. A amostra alagoana contou com 10 municípios, cujas desigualdades sociais são bem conhecidas de todos nós, com reflexos impactantes nas condições de oferta da educação básica nas redes municipais de ensino. O baixo índice de desenvolvimento humano (IDH) e o baixo Ideb desses municípios revelam o quanto ainda são necessárias políticas públicas de cunho social para mudar esse quadro.

$\mathrm{O}$ incremento de recursos aos municípios em Alagoas por meio do PAR, para além da assistência financeira obrigatória prevista no ordenamento constitucional-legal, contribuiu para o alcance do objetivo maior do Plano de Metas, que é a melhoria da qualidade da educação básica. Não falamos apenas das transferências voluntárias oriundas dos convênios de assistência financeira, como aqueles relativos ao programa ProInfância e ao programa Caminho da Escola (transporte escolar). Falamos também de todas as formas de assistência técnica, assim compreendidas no PAR, voltadas à formação de professores e demais profissionais de apoio, à disponibilização de materiais e de equipamentos para as redes de ensino. Essas formas de assistência "têm se apresentado como possibilidades reais de criar condições mais adequadas para mudar as realidades educacionais" (PERGHER; MACHADO, 2010, p. 18).

Mesmo considerando-se reduzida, em termos percentuais, a assistência financeira do MEC aos municípios de Alagoas, o impacto que esses recursos causaram nas receitas da educação não deixa de ser significativo, representando, em alguns municípios alagoanos, percentuais que correspondem a mais de $20 \%$ das receitas de manutenção e desenvolvimento do ensino. Os principais recursos financeiros repassados são dos convênios firmados para aquisição de veículos para o transporte escolar, no programa Caminho da Escola, e construção de escolas infantis, do programa ProInfância.

Identificamos, contudo, as fragilidades que um plano de caráter inovador com essa dimensão pode apresentar, pois tanto da parte dos municí- pios quanto do MEC houve atraso ou não foram executadas as subações nos prazos previstos. Não foi possível, entretanto, apurar profundamente as razões pelas quais isso ocorreu; todavia sublinhamos as dificuldades de implementação das ações por parte das equipes municipais e as indefinições ou os atrasos do MEC na implementação de ações de assistência sob sua responsabilidade. De acordo com os dados levantados na pesquisa, a falta de atendimento do MEC e as dificuldades de ordem técnico-administrativa ou operacional foram os principais limites à execução das subações pelos municípios da amostra.

Paraíba. O estado da Paraíba possui 223 municípios, dos quais 191 têm atendimento prioritário do Ministério da Educação por meio do Plano de Metas Compromisso Todos pela Educação. Eles integraram a amostra da pesquisa 35 municípios paraibanos prioritários, quase todos com um contexto socioeconômico crítico, com indicadores de desenvolvimento humano que apontam para condições de vida bastante precárias da população. Nesse sentido, os dados permitem relacionar a desigualdade educacional com as condições socioeconômicas desfavoráveis dos municípios.

A execução das ações e subações - sejam elas de responsabilidade dos municípios, sejam de responsabilidade do MEC - não ocorreu no tempo previsto no plano.

Na dimensão da gestão educacional do PAR, a responsabilidade de subações é predominantemente dos governos locais, uma vez que se compõem, basicamente, de ações de elaboração de instrumentos, como planos orientadores da execução das subações, documentos de divulgação, projetos de lei e reuniões. Contudo os dados demonstram que as equipes municipais ainda possuem dificuldades significativas para executar o plano nos aspectos vinculados à gestão, pois a maioria das subações, passados três anos do início dessa política, ainda se encontrava na situação de não iniciada.

A segunda dimensão do PAR, a formação inicial e continuada de professores e de profissionais de serviço e apoio escolar, pode ser entendida como tendo sido o foco de atenção dos municípios da amostra desse estado, tendo em vista que os municípios, em geral, manifestaram a necessidade de capacitação para grande parte dos professores 
que atuam na educação básica. Todavia menos de $30 \%$ das ações estavam em andamento, revelando as dificuldades administrativas e operacionais que tanto os municípios quanto o MEC tiveram para executá-las nos prazos previstos.

A terceira dimensão do PAR diz respeito às práticas pedagógicas e à avaliação. E os municípios são responsáveis pela execução da maioria delas. Do total de subações, os municípios ficaram responsáveis por $69 \%$, o que é compreensível, já que a maior parte das ações está diretamente relacionada aos processos pedagógicos escolares. Entretanto é preciso salientar que, até o primeiro semestre de 2010, grande parte das subações não havia sido iniciada.

$\mathrm{Na}$ dimensão da infraestrutura física e dos recursos pedagógicos, estão programas e ações destinados a apoiar a reestruturação das redes físicas das escolas públicas, e representam parte das condições para a melhoria de acesso e permanência da educação, visando à superação das desigualdades na oferta e no padrão de qualidade do ensino nas escolas públicas, objetivo maior do PAR. No entanto, considerada a situação precária dos municípios da amostra no que se refere a orçamento educacional, podemos dizer que a assistência financeira do MEC apresenta um percentual muito baixo nessa dimensão, que, dentre todas, incorpora o maior volume de recursos financeiros.

Rio Grande do Sul. O Rio Grande do Sul está na lista dos estados mais ricos do país, porém o território gaúcho apresenta desigualdades bastante expressivas no que tange a desenvolvimento econômico, social e educacional. Os municípios priorizados pelo MEC somaram 143 dos 496 municípios gaúchos, e 38 fizeram parte da amostra do estudo.

A análise dos indicadores da dimensão da gestão educacional permitiu perceber traços contraditórios, afirmando concepções que emergem dos movimentos sociais, mas também as proposições advindas do gerencialismo. A primeira é representada pela indução do cumprimento de uma concepção de gestão democrática disputada pelos movimentos sociais e confirmada na legislação, incorporando a implementação de mecanismos de controle social e de planejamento fundamentados pela aplicação correspondente dos recursos destinados à educação, bem como o incentivo às parcerias estabelecidas entre escolas, comunidade e instituições afins. A segunda é expressa por meio do incentivo às parcerias público-privadas, bem como da consideração, no texto da política, dos resultados dos alunos nas avaliações oficiais. Esse é um aspecto polêmico do PAR e fator de resistência por parte de diversos segmentos ligados à educação, por fazer relação direta entre desempenho do estudante e práticas pedagógicas, sem a consideração de outros fatores sociais que influenciam no processo.

A dimensão da formação inicial e continuada de professores e de profissionais de serviço e apoio escolar foi a que teve maior frequência de escolha de subações por parte dos municípios da amostra do Rio Grande do Sul. Nessa dimensão, a maior parte das subações era de responsabilidade do MEC, sendo o papel dos municípios basicamente referido a diagnósticos e mapeamentos da formação dos professores e demais profissionais. A análise revelou a pouca prática dos municípios na elaboração de planos de formação de professores e demais profissionais da educação. Contudo identificamos, igualmente, problemas com o Ministério da Educação para cumprir com a responsabilidade assumida nas formações, com cursos ofertados no PAR e não efetivados.

Dentre as quatro dimensões do PAR, a de práticas pedagógicas e avaliação apresentou $\mathrm{O}$ menor número de indicadores e subações. Além disso, também foi essa dimensão a que menos teve ações e subações registradas pelos municípios. Alguns municípios não registraram ações e subações nesse campo.

$\mathrm{Na}$ dimensão da infraestrutura física e recursos pedagógicos, a análise evidencia o foco dos municípios. Essa dimensão, mesmo não comportando o maior número de indicadores, foi a mais esperada e requisitada pela marcação de indicadores. Nela foram contemplados indicadores e ações/subações referentes a mobiliário, salas de recursos, laboratórios de informática e a construção de escolas de educação infantil por meio do programa ProInfância. Podemos dizer que o acesso à assistência financeira e técnica dessa dimensão foi a razão principal pela qual muitos municípios aderiram ao Plano de Metas.

Com base na análise dos 38 municípios da amostra do Rio Grande do Sul, e considerando as 
situações de execução em andamento e concluída para as ações/subações relativas ao período de 2008/1 a 2010/1, podemos argumentar que persiste a cultura de planos de gaveta em educação. Nos municípios analisados, o planejamento ainda não é a ferramenta orientadora da ação pública baseada em um diagnóstico significativo da situação da educação municipal. Todavia é preciso considerar que os municípios tiveram um papel mais passivo no que tange à adesão à política, sem participação na sua formulação; com efeito, cumpriram suas responsabilidades com a realização de subações de forma mais efetiva do que o MEC. De um total de 380 subações do PAR nas situações concluída e em andamento, $74,5 \%$ foram realizadas pelos municípios.

Santa Catarina. Na fase de elaboração do Plano de Ações Articuladas dos 63 municípios priorizados do estado de Santa Catarina, apenas 16 tiveram assessoria de consultores contratados por meio de convênio firmado entre o Ministério da Educação e a Unesco. O estado possui 293 municípios, o que significa que menos de $5 \%$ do total contou com a assistência técnica na elaboração do PAR.

Essa foi a primeira vez que o MEC reuniu um conjunto considerável de programas educacionais, da sua alçada ou da alçada de outros ministérios, e o oferta aos municípios de modo relativamente generalizado e condicionado à adesão a diretrizes e metas. Desse modo, seria necessário não deixar desassistido nenhum município brasileiro no processo de elaboração, independentemente do Ideb, pois tal assessoria tem se mostrado relevante para a consolidação da política. Em Santa Catarina, a pouca ou nenhuma assistência técnica para elaboração do PAR limitou-a com orientações mínimas necessárias para um bom planejamento.

A ausência de assessoria em alguns municípios evidenciou a dificuldade no entendimento da lógica de elaboração do PAR, o que acarretou a elaboração de planos com reduzido número de ações e subações, sem conexão com a realidade local e muitas vezes sem uma lógica do ponto de vista da articulação de ações e subações. Se analisados do ponto de vista de um planejamento multidimensional em médio prazo, não se configuram como um planejamento, ou seja, não foram construídos com base em uma lógica apoiada em um diagnóstico. Esse fato foi revelado no acompanhamento do monitoramento do PAR, quando foi disponibilizada assistência técnica, por meio de consultores, a todos os municípios priorizados. Nesse período, a atuação do consultor muitas vezes envolveu retomar a elaboração para corrigir cursos que foram avaliados como inadequados ao contexto ou à realidade municipal.

Nesse sentido, consideramos que é de suma importância, no processo de implementação de uma política - seja o PAR, seja outra política que envolva um planejamento que considere a colaboração entre entes federados -, a atuação de técnicos e assessores que conheçam a política e sejam capazes de orientar os sujeitos que irão executá-la.

Um problema relatado pelos técnicos que apoiaram o monitoramento em Santa Catarina, principalmente em municípios de pequeno porte, foi a dificuldade de as equipes locais lidarem com o Simec, módulo PAR.

Outro obstáculo à execução do PAR foi o processo de eleições municipais que ocorreu em 2008. Esse processo resultou em mudanças na gestão educacional local, e muitos secretários municipais e técnicos das secretarias municipais de educação mais familiarizados com o planejamento foram substituídos, e as informações não foram repassadas. Os novos técnicos e dirigentes municipais, diante desse contexto, queriam realizar um novo diagnóstico, para, consequentemente, elaborar um novo plano.

Por fim, destacamos o número reduzido de recursos humanos nas secretarias municipais de educação para dar conta das demandas já existentes e ainda acompanhar as novas demandas que vieram com a execução do PAR, bem como a falta da cultura de planejamento das ações nessas secretarias e as indefinições sobre a política educacional norteadora das ações.

\section{Comentários finais... e início de novas conversas}

Com o Plano de Metas, há uma proliferação de ações de assistência técnica (AT) e assistência financeira (AF) voluntárias do MEC à educação 
básica das redes públicas estaduais e municipais; há maior publicização de critérios de atendimento nessa assistência; há estabelecimento de condicionalidades para que os governos subnacionais acessem recursos de assistência do MEC. Diferentemente dos planos de trabalho anuais (PTAs) - instrumentos-chave das ações de assistência do MEC a municípios e estados antes da implantação do Plano de Metas/PAR -, não são os entes assistidos (governos estaduais e prefeituras) que propõem esse ou aquele projeto/ação, mas é o MEC que disponibiliza um menu de programas e ações, com especificação de ações dos estados ou municípios a serem desenvolvidas antes, concomitantemente ou após a ação do MEC.

Utilizamos o termo menu para designar que existem possibilidades de escolha de ações; no entanto tais escolhas não são ilimitadas, pois se restringem aos itens do menu, quer dizer, às ações de assistência técnica ou financeira oferecidas no plano de ações. Por certo, há que se considerar também que o menu não ficou estático ao longo do período, pois foram sendo adicionados programas e ações, inclusive resultantes de demandas da sociedade civil e de dirigentes educacionais locais, além daqueles adicionados pela proposição de gestores do próprio MEC e, quiçá, de outros órgãos governamentais federais.

Nossa pesquisa evidencia o alto percentual de ações que não foram concluídas, para o qual concorreram limites à execução ligados a fragilidades do MEC e das administrações locais da educação. Com isso, podemos dizer que as adesões à nova política são imperfeitas de ambas as partes: os entes resignificam as ações previstas sob sua responsabilidade, podem não cumprir ou cumprir parcialmente o que registraram nos planos, e há uma série de motivos para isso; no MEC, as adesões também são imperfeitas, por tudo quanto envolve a concepção e a efetiva disponibilização de ações por diferentes órgãos e suas subdivisões. Se não há uma coincidência de representações da política entre MEC e governos locais, podemos cogitar também uma não coincidência entre atores dentro do próprio MEC.

As considerações anteriores não são feitas supondo que uma política deva ser implementada tal e qual foi concebida, ou que há organicidade dentro de um ministério; a literatura de análise de políticas públicas tem adjetivado as políticas como comumente descontínuas, contraditórias, caóticas, incompletas, descoordenadas - a esse respeito ver, por exemplo, Muller e Surel (2002), Muller (2006) e Frey (2000). Não estamos dizendo como deve ser, ou que deve ser perfeito; queremos apontar como é e chamar a atenção de que, em nossos estudos das políticas públicas, o que mais comumente encontramos são adesões imperfeitas às políticas, mais do que não adesões.

E o que é o Plano de Metas/PAR? O que está enunciado no Decreto 6.094/07? A resposta é positiva, mas temos que considerar que, como ação pública, a política Plano de Metas/PAR é atualizada pelas traduções que os atores, em diferentes posições e níveis, realizam no contínuo movimento de sua formulação-implementação.

A discussão da autonomia dos governos subnacionais e das escolas, bem como das relações intergovernamentais, talvez possa se beneficiar dessa compreensão. É certo que a política proposta (continuamente reconfigurada) demarca um campo de possibilidades, seja pelo conteúdo do PAR, seja pela delimitação de responsabilidades ou pelas relações intergovernamentais que sua operacionalização envolve. Entretanto demarcar, em políticas públicas, não é determinar, não é antecipar todas as operações e resultados; é estabelecer algumas balizas dentro das quais diferentes interpretações podem ocorrer. Aqui, é pertinente a reflexão de Stephen Ball sobre a política como texto (sujeita à interpretação dos atores) e a política como discurso. A política tomada como texto supõe uma pluralidade de leituras, quer dizer, interpretações diversas que geram práticas diversas. A política como discurso sugere que essas interpretações não são ilimitadas, totalmente abertas, pois o raio de possibilidades de interpretação está demarcado pelas referências, atribuições de atores, procedimentos e recursos postos/dispostos pela política tal como concebida (BEECH, 2009).

Tratamos, aqui, de uma política intergovernamental. Assim, cabe também uma reflexão final sobre a pesquisa em política educacional que tem como objeto política(s) intergovernamental (ais).

A noção/conceito de relações intergovernamentais diz respeito às relações entre diferentes níveis 
de governo, variando, na produção acadêmica, a abordagem de tais relações. O estudo dos arranjos administrativos e legais que regem as relações intergovernamentais é importante, mas, conforme argumenta Souza (2002), uma orientação teórica que possa avançar no estudo das relações intergovernamentais deveria levar em conta a compreensão de como os conflitos são negociados, quer dizer, a negociação política entre os grupos, com ênfase para os atores situados nas diferentes esferas de governo previstas no nosso federalismo. $\mathrm{O}$ ordenamento constitucional-legal é uma referência, sem dúvida, como também o são os conteúdos das políticas, o sistema e as sistemáticas que se estabelecem na implementação das políticas intergovernamentais. O desafio seria compreender as políticas de concepção e/ou execução compartilhada no bojo de uma abordagem de relações intergovernamentais que inclua a (mas não se esgote na) dimensão política das relações, ou seja, a abordagem das relações de poder na negociação de conflitos, considerando a política (jogo político, padrões, formas, formatos de articulação) no campo estudado (no nosso caso, a educação) e na sua relação com a política em geral.

Como último comentário, queremos retornar ao tema da pesquisa social de tipo de avaliação. Figueiredo e Figueiredo (1986), ao fazerem uma distinção entre avaliação política e avaliação de políticas, chamam a atenção para a importância, nos estudos de políticas, da avaliação política dos princípios que regem a(s) política(s) em foco. A avaliação política, segundo os autores, envolve a análise da elucidação do critério ou dos critérios que fundamentam determinada política, suas razões; uma análise das razões envolve indagar sua relevância, quer dizer, sua contribuição à distribuição de bem-estar.

$\mathrm{O}$ art. $1^{\circ}$ do decreto 6.094/07 enuncia:

O Plano de Metas Compromisso Todos pela Educação (Compromisso) é a conjugação dos esforços da União, Estados, Distrito Federal e Municípios, atuando em regime de colaboração, das famílias e da comunidade, em proveito da melhoria da qualidade da educação básica. (BRASIL, 2007, grifos nossos).

Como já dissemos anteriormente, uma política que se direcione à melhoria da qualidade da educação básica agrega apoios, já que esse avanço vem sendo clamado há décadas por diferentes segmentos sociais e da sociedade política do país. Além disso, também é potencialmente agregadora de apoios uma política que proponha colaboração entre diferentes níveis de governo e conjugação de esforços destes com famílias e comunidades. Se adicionarmos a essas razões as 28 diretrizes estabelecidas no decreto citado - as quais abrangem aspectos relacionados ao acesso e à permanência na escola, à organização do trabalho pedagógico, à formação e à carreira dos profissionais da educação, à gestão das escolas e das redes de ensino, entre outros -, também chegaremos à conclusão de que há razões relevantes que fundamentam a política.

Seguindo novamente os argumentos de Figueiredo e Figueiredo (1986), a avaliação política, contudo, não se esgota no reconhecimento do consenso social, ou de um consenso social suficiente, em relação às razões ou aos princípios de uma política, pois se deve atentar para a compatibilidade entre eles e para a sua consistência em relação aos mecanismos institucionais previstos no âmbito da política.

Nossa pesquisa contemplou a avaliação de uma política, mais especificamente, uma avaliação de resultados da execução do PAR numa amostra de municípios. Fazemos parte de uma equipe que vem trabalhando com municípios brasileiros, em apoio à elaboração e à implementação do PAR, desde 2007, portanto reconhecemos como relevantes as razões que fundamentam a política. A avaliação realizada tem sido útil para nosso trabalho de assistência técnica aos municípios; esperamos que também o seja para fomentar a discussão de alternativas e estratégias que deem mais consistência à busca de compatibilidade entre as razões e os princípios do Plano de Metas Compromisso Todos pela Educação e os recursos e mecanismos institucionais que sua implementação requer. 


\section{REFERÊNCIAS}

BATISTA, Neusa C. et al. Implementação de planos de ações articuladas em municípios do Rio Grande do Sul. In: FARENZENA, Nalú (Org.). Implementação de planos de ações articuladas municipais: uma avaliação em quatro estados brasileiros. Pelotas: Gráfica Universitária UFPel, 2012. p. 91-120.

BEECH, Jason. A internacionalização das políticas educativas na América Latina. Currículo sem Fronteiras, v. 9, n. 2, p. 32-50, jul./dez. 2009.

BRASIL. Decreto $\mathbf{n}^{0}$ 6.094, de 24 de abril de 2007. Dispõe sobre a implementação do Plano de Metas Compromisso Todos pela Educação, pela União Federal, em regime de colaboração com Municípios, Distrito Federal e Estados, e a participação das famílias e da comunidade, mediante programas e ações de assistência técnica e financeira, visando à mobilização social pela melhoria da qualidade da educação básica. Brasília, DF, 2007. Disponível em: $<$ http://www.planalto.gov.br/ccivil_03/_ato2007-2010/2007/decreto/d6094.htm>. Acesso em: 15 jul. 2012.

COHEN, Ernesto; FRANCO, Rolando. Avaliação de projetos sociais. Petrópolis: Vozes, 2008.

FARENZENA, Nalú (Org.). Implementação de planos de ações articuladas municipais: uma avaliação em quatro estados brasileiros. Pelotas: Gráfica Universitária UFPel, 2012.

FIGUEIREDO, Marcus Faria; FIGUEIREDO, Argelina Maria Cheibub. Avaliação política e avaliação de políticas: um quadro de referência teórica. Análise e Conjuntura, Belo Horizonte, v. 1, n. 3, p. 107-127, set./dez. 1986.

FRANÇA, Damiana M. C. et al. Implementação de planos de ações articuladas em municípios da Paraíba. In: FARENZENA, Nalú (Org.). Implementação de planos de ações articuladas municipais: uma avaliação em quatro estados brasileiros. Pelotas: Gráfica Universitária UFPel, 2012. p. 65-90.

FREY, Klaus. Políticas públicas: um debate conceitual e reflexões referentes à prática da análise de políticas públicas no Brasil. Planejamento e Políticas Públicas, Brasília, IPEA, n. 21, p. 211-259, jun. 2000.

MACHADO, Maria Goreti F. et al. Implementação de planos de ações articuladas em municípios de Alagoas. In: FARENZENA, Nalú (Org.). Implementação de planos de ações articuladas municipais: uma avaliação em quatro estados brasileiros. Pelotas: Gráfica Universitária UFPel, 2012. p. 31-64.

MOKATE, Karen Marie. Convirtiendo el "monstruo" en aliado: la evaluación como herramienta de la gerencia social. Washington, D.C.: Instituto Interamericano para el Desarrollo Social (INDES), 2000.

MULLER, Pierre. Les politiques publiques. Paris: PUF, 2006.

; SUREL, Yves. Análise das políticas públicas. Pelotas: EDUCAT, 2002.

PERGHER, Calinca; MACHADO, Maria Goreti. O impacto de ações de assistência financeira do MEC em municípios de Alagoas. São Paulo, 2011 (Trabalho apresentado no XXV Simpósio Brasileiro e II Congresso Ibero-Americano de Política e Administração da Educação).

ROSSI, Alexandre J. et al. Implementação de planos de ações articuladas em municípios de Santa Catarina. In: FARENZENA, Nalú (Org.). Implementação de planos de ações articuladas municipais: uma avaliação em quatro estados brasileiros. Pelotas: Gráfica Universitária UFPel, 2012. p. 153-164.

SIMEC. Sistema de Monitoramento de Informações do Ministério da Educação. Banco de dados do PAR 20082011. Disponível em: <http://simec.mec.gov.br/>. Acesso em: 2012.

SOUZA, Celina. Governos e sociedades locais em contextos de desigualdades e descentralização. Ciência \& Saúde Coletiva, v. 7, n. 3, p. 431-442, 2002.

Recebido em 20.07.12

Aprovado em 22.08 .12 